\title{
A computer-based simulation and evaluation: Applying an automatic sprinkler system for extinguishing scooter fires in arcade areas
}

\author{
Sheng-Chieh Lee****, Ching-Yuan Lin*, Ying-Ji Chuang* and Yuan-Shang Lin** \\ * Department of Architecture, National Taiwan University of Science and Technology, Taipei, Taiwan 10607 \\ ** Graduate School of Disaster Management, Central Police University, Taoyuan City, Taiwan 33304 \\ **־ Corresponding Author : D10813002@mail.ntust.edu.tw
}

Submitted : 18/04/2020

Revised :23/01/2021

Accepted :07/03/2021

\begin{abstract}
In Taiwan, arcade buildings function as areas for parking scooters, spaces for markets, and walkways for pedestrians. In recent decades, arcade fires have caused many cases of serious casualties due to the likely direction of fire that spreads from the first floor up, which hinders the evacuation routes. The majority of fire prevention research has focused on confined spaces or rooms instead of arcade areas. Specifically, the controlling of fire spreads that are caused by scooters in arcade areas has been rarely discussed. The variables of spaces, Response Time Index, and sprinkler activation temperatures are modeled in five fire scenarios with the Fire Dynamics Simulator software to simulate the real arcade fires in this paper. The results show that (1) setting an automatic sprinkler system can effectively suppress the arcade fires, (2) the quick response sprinkler $\mathrm{RTI} \leqq 50$ is the most effective type, and the result is similar to RTI $=25$, and (3) the sprinkler settings with either 2.3 meters or 2.6 meters do not have significant effects on heat release rates.
\end{abstract}

Keywords: Arcade; Scooter fires; Sprinkler system; Fire dynamics simulator; Simulations

\section{INTRODUCTION}

In Southeast Asia, including Taiwan, there exists a typical form of building, which features the part of the first floor facing the street designed as a sidewalk with the second floor and its top known as "arcade" (all "arcades" mentioned in this article refer to this specific type of building feature). Many buildings here located next to sides of major roads are linked together with arcades, which protects the pedestrians from direct exposure to the humid and hot weather of Southeast Asia [1]. Lee [2] Investigation of the cause of fire in arcades of Taiwanese buildings have led to the discovery that majority of fire cases are artificial. It is calculated that there have been 465 cases within 5 years, 217 of which is arson. With a ratio of $47 \%$, it is the highest of all categories. $66 \%$ of the cases happened in between 22:00 and 6:00. Lee [3] investigation of 824 major roads of New Taipei City's five downtown areas reveals that $52 \%$ of the people park their scooters in arcade areas. The first floors of arcade buildings are usually for commercial use, as they are suitable for window displays. It is common for owners to set up large signboards outside the arcades or even seal the windows for commercial use. Such design reinforces the spread of fire to higher levels [4], which hinders the evacuation routes [5]. From 2009 to 2018, the statistical data from the National Fire 
Agency, Ministry of the Interior (Taiwan) indicates that arcade fires have caused 24 fatalities and 99 injuries (Figure 1). Also, as arcades are privately owned areas open to the public, especially for those in marketplaces, it is unclear who is responsible for the fire safety, which further increases the danger of fire incidents under the arcades [3]. A research [6] done on arcade scooter fire shows that when such fire happened, the ceiling of arcade can reach up to $576{ }^{\circ} \mathrm{C}$, radiant heat of $8.7 \mathrm{~W} / \mathrm{cm}^{2}$, flame height of over $5 \mathrm{~m}$, and a spread rate of fire that reaches $62 \mathrm{~cm} / \mathrm{min}$. With such a high temperature, radiant heat, and flame height, the fire can easily spread to higher levels through the flammable board signs. Also, the closely parked scooter would boost the spread of fire horizontally. Review shows that parking scooters in arcade areas has been a long-running factor of fire hazards in old apartments in Taiwan. Under these circumstances (shown in Figure 2), fire safety provisions for the scooters underneath the arcades would be the most practical solution to protecting the citizens from any sort of casualties and property loss in the event of a scooter fire $[7,8]$.

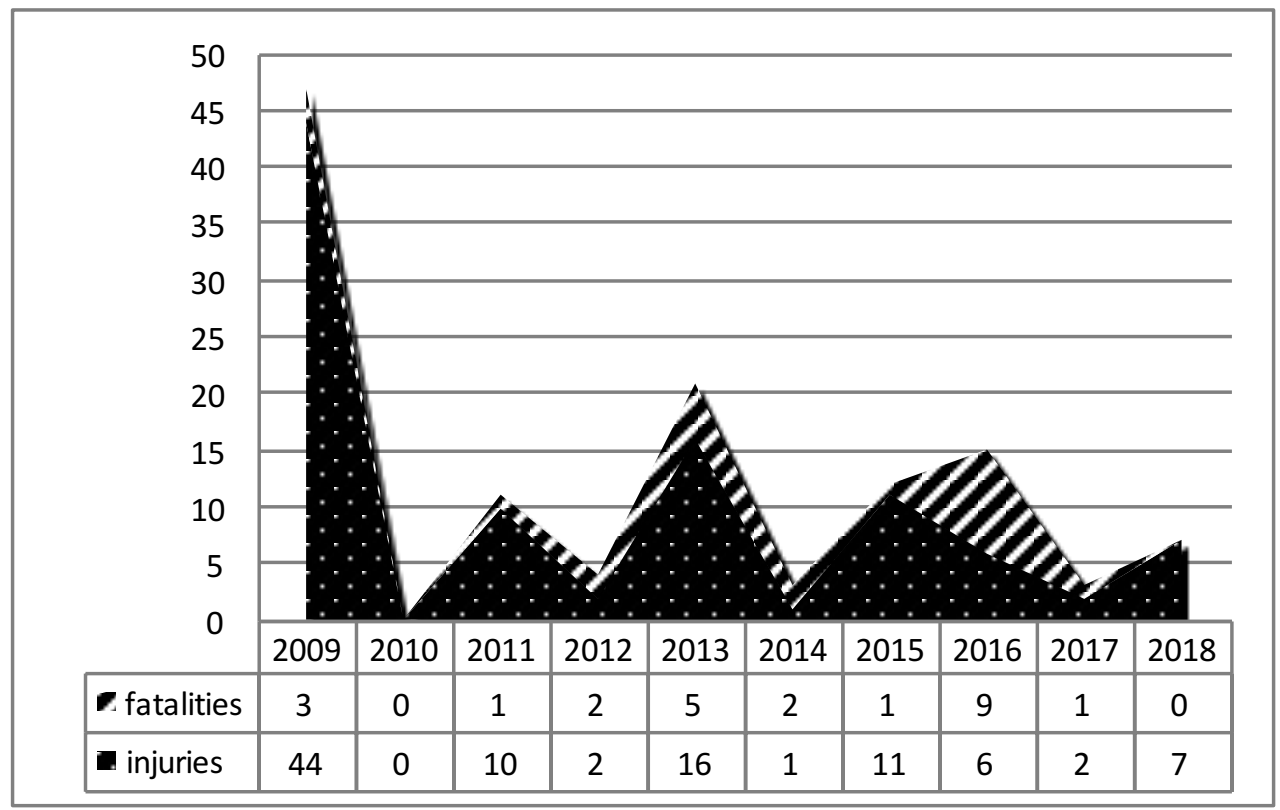

Figure 1. The descriptive data of arcade fires from 2009 to 2018 in Taiwan.

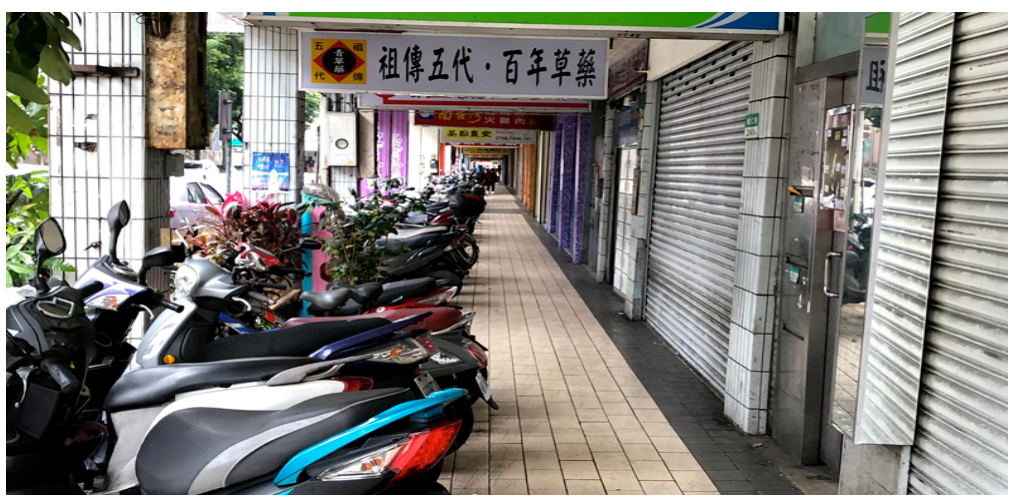

Figure 2. The arcade buildings function as areas for parking scooters and walkways for pedestrians. 
Most fire researches focus on fires in confined space [8,9,10,11], where heat accumulation and flammable gases are limited [12]; however, this simulation studies fires in open space, where mixtures of gaseous fuels and air could easily reach the flammability limit. With a lack of sources discussing open area fires, this research chose to utilize the FDS (Fire Dynamics Simulator) software [13] to monitor the effects of the temperatures, both indoors and outdoors, and the flow of gases and air in the event of fire [14]. The Response Time Index (RTI), spacing, and the activation temperature of the sprinklers are set as the main parameters of this study in order to understand the fire control abilities of the sprinklers under different settings. The 3 main goals of the study are: (1) the effects of the installed sprinklers on controlling the temperature and the heat release rate of the scooter fires. (2) In the case of a scooter fire beneath the arcade, does the fire control ability of the sprinkler vary with RTI? (3) The effects that the sprinklers have on the maximum temperature of the fire scene and the heat release rate of the fire when using sprinklers with the same RTI but different activation temperatures.

\section{METHODS}

\subsection{Settings of the Building and Sensors}

This research focuses on a five-story building. The first floor is a store, the second floor and above are for residents, and two households that are on the same floor share one staircase. In order to conduct a realistic simulation, this research will design simulation based on the data provided by "Experimental Study on Spread of Fires Started by Scooters in the Sheltered Arcade of Arcade-Style Buildings" by Professor Lin's research team [14]. The arcade is $16 \mathrm{~m} \times 5 \mathrm{~m} \times 3 \mathrm{~m}$, and there are 20 scooters parked on the side of the road below the building. Figure 3. shows the location of twenty $50 \mathrm{cc}$ scooters in the arcade and how to set up an ignition location. The building entrance's size is $2.8 \mathrm{~m} \times 2.8 \mathrm{~m}$. Using an FDS simulation of the five-story building as a model, this experiment sets a similar grid size of $30 \mathrm{~cm} \times 10 \mathrm{~cm} \times 20 \mathrm{~cm}$, and the total number of grids is 1.5 million. The computational time for one case was 600 seconds, and the scenario, which was compared in five different cases (scenarios 1, 2, 3, 4, and 5 of Table 1). In this simulation, it is assumed that there are no miscellaneous items placed along the staircase or any illegal constructions; this is done to avoid possible complications of the results. Temperature sensors are also set at $5 \mathrm{~cm}$ under the ceiling and along the arcade; they are noted as TC- 1 to TC-6 with $2.6 \mathrm{~m}$ separation between each sensor. The fire is set to start at $1.5 \mathrm{~m}$ to the right of the ground directly under TC-1 and to spread towards the right. In order to observe the flow of smoke into the staircase and the changes in the temperature of the gases at the 1st-floor entrance, there are two sensors in the middle of the main entrance at different heights of 1.6m (an average person's height), noted as TC-21, and $2.6 \mathrm{~m} \mathrm{(20} \mathrm{cm} \mathrm{under} \mathrm{the} \mathrm{ceiling),} \mathrm{noted}$ as TC-22. The temperature sensors stated above are shown in Figure 4.

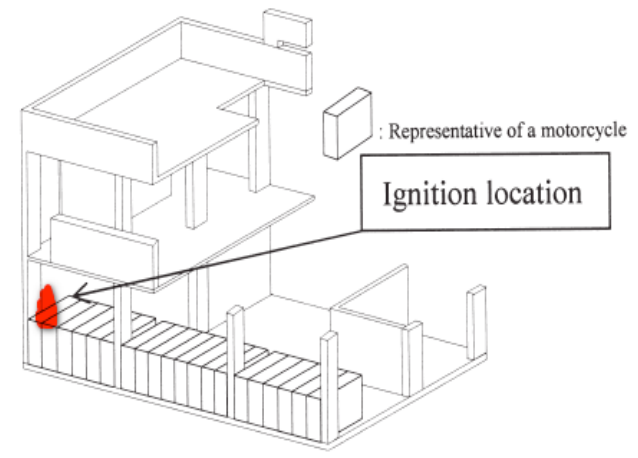

Figure 3. Testing location of twenty 50cc scooters in the arcade. [14] 
Table 1. The design of different scenarios

\begin{tabular}{|c|c|c|}
\hline Scenarios & Variable & Constants \\
\hline Scenario 1 & $\mathrm{RTI}=100(\mathrm{~m}-\mathrm{s})^{1 / 2}$ & $\begin{array}{c}\text { Activation temperature }=68^{\circ} \mathrm{C} \\
\text { Distance between sprinklers }=2.6 \mathrm{~m} \\
\text { Flow rate }=80 \mathrm{~L} / \mathrm{min}\end{array}$ \\
\hline Scenario 2 & $\mathrm{RTI}=50(\mathrm{~m}-\mathrm{s})^{1 / 2}$ & $\begin{array}{c}\text { Activation temperature }=68^{\circ} \mathrm{C} \\
\text { Distance between sprinklers }=2.6 \mathrm{~m} \\
\text { Flow rate }=80 \mathrm{~L} / \mathrm{min}\end{array}$ \\
\hline Scenario 3 & $\mathrm{RTI}=25(\mathrm{~m}-\mathrm{s})^{1 / 2}$ & $\begin{array}{c}\text { Activation temperature }=68^{\circ} \mathrm{C} \\
\text { Distance between sprinklers }=2.6 \mathrm{~m} \\
\text { Flow rate }=80 \mathrm{~L} / \mathrm{min}\end{array}$ \\
\hline Scenario 4 & Activation temperature $=72^{\circ} \mathrm{C}$ & $\begin{array}{c}\text { RTI }=25(\mathrm{~m}-\mathrm{s})^{1 / 2} \\
\text { Distance between sprinklers }=2.6 \mathrm{~m} \\
\text { Flow rate }=80 \mathrm{~L} / \mathrm{min}\end{array}$ \\
\hline Scenario 5 & $\begin{array}{l}\text { Distance between sprinklers }= \\
\qquad 2.3 \mathrm{~m}\end{array}$ & $\begin{array}{l}\mathrm{RTI}=100(\mathrm{~m}-\mathrm{s})^{1 / 2} \\
\text { Activation temperature }=68^{\circ} \mathrm{C} \\
\text { Flow rate }=80 \mathrm{~L} / \mathrm{min}\end{array}$ \\
\hline
\end{tabular}

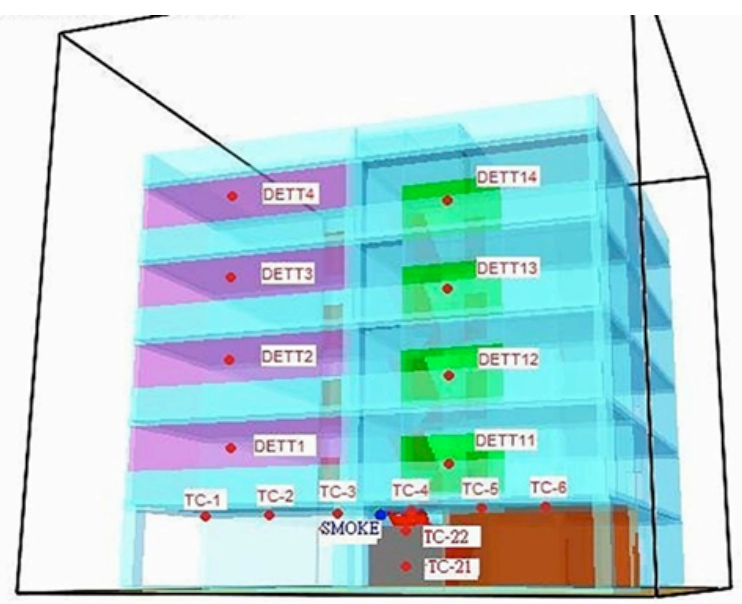

Figure 4. The positioning of the temperature and smoke sensors

(Simulation of this study).

\subsection{Scenarios of the Simulation}

The NFPA 13 classifies sprinklers based on their thermal sensitivity, which is derived from the RTIs of the sprinklers [15]. Fast response, standard response, and special response are the three different types for the sprinklers [16]. In order to understand the difference created by the RTIs of the sprinklers, this research will utilize three 
sprinklers with RTIs of $25(\mathrm{~m}-\mathrm{s})^{1 / 2}, 50(\mathrm{~m}-\mathrm{s})^{1 / 2}$, and $100(\mathrm{~m}-\mathrm{s})^{1 / 2}$ for comparison. This value of RTI can help to verify the concept that a fast response sprinkler is more effective and efficient than the standard response sprinkler. This research utilized a wet pipe sprinkler system. According to article 50 of Installation Standards: "The water output of a nozzle should be more than $80 \mathrm{~L} / \mathrm{min}$, and pressure more than $1 \mathrm{kgf} / \mathrm{cm}^{2}$ or $0.1 \mathrm{Mpa}$ ". Therefore, the parameters of the sprinklers (ID: Acme Sprinkler) used in the FDS are set at FLOW_RATE $=80$, RTI $=25,50$, 100, ACTIVATION TEMPERATURE at 68,72 , and SPRAY ANGLE at 30 and 80 . The distance between the nozzles is set according to a distance of $2.6 \mathrm{~m}$ ( or $2.3 \mathrm{~m}$ ) Installation Standards. Five different scenarios are designed for this research and are described in Table 1.

\subsection{Settings of the Fire}

Heat release rate, which is usually measured in kilowatt $(\mathrm{kW})$ or megawatt $(1 \mathrm{MW}=238 \mathrm{kcal} / \mathrm{sec})$, is the energy that is released when the flammable materials are burning, the driving force of the flow of heat and smoke of a fire, and also the source of high temperature and spreading of fires [17]. Without the effects of the sprinklers, the heat release rate of this simulation, as shown in Figure 5, is designed with reference to the results of the full-scale fire experiment done by Professor Lin et al. [14], as shown in Figure 6. Due to the fact that the heat release rate from Professor Lin's experiment remains close to zero until the 5th minute, the heat release rate for this simulation will begin with the heat release rate at 5 minutes into Professor Lin's experiment. To incorporate a realistic cooling effect provided by the sprinkler system to this simulation, this research will refer to the E-Coefficient provided by the results of Zheng's FDS simulation of motorcycle fires under the effects of sprinklers [18].

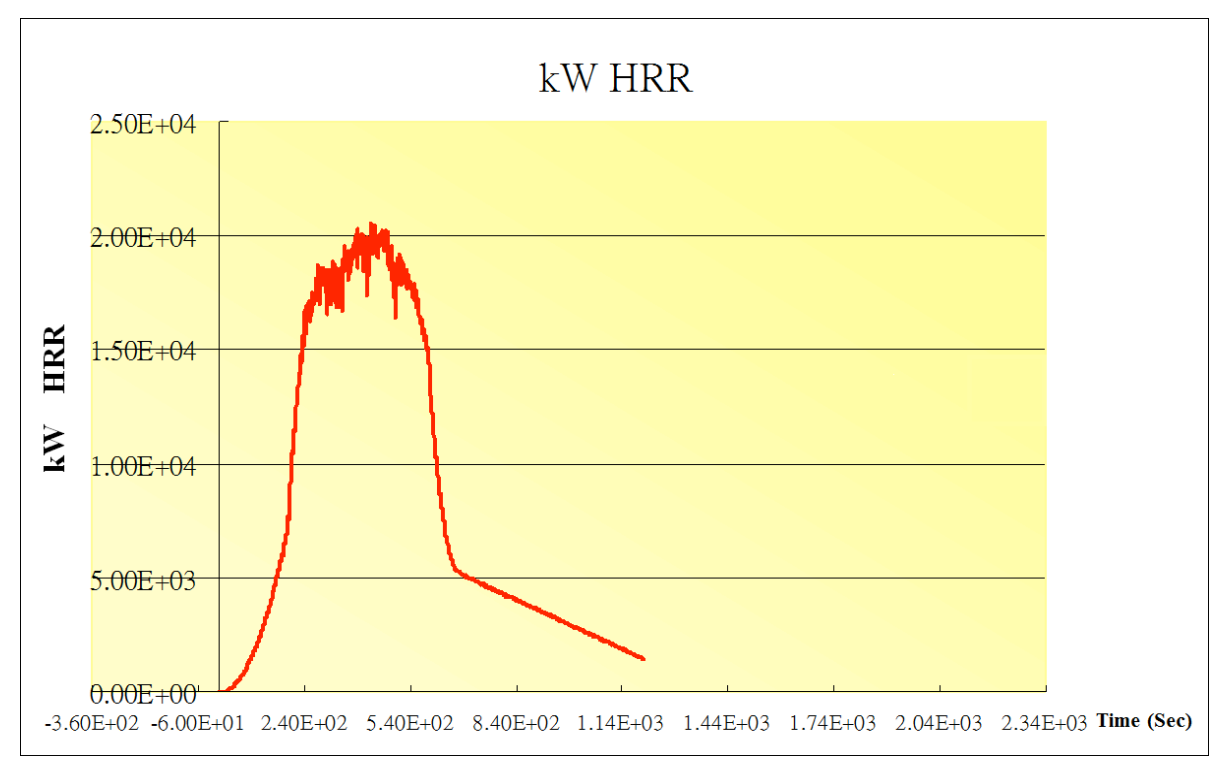

Figure 5. This study heat release rate used for the simulation. 


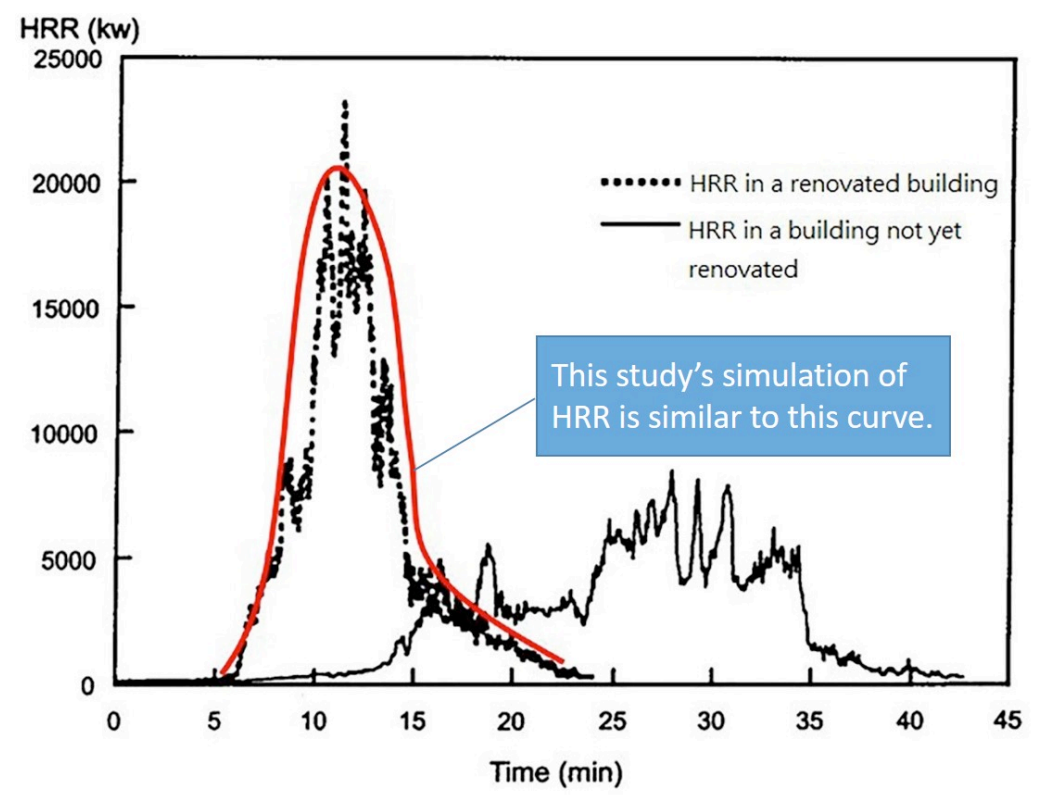

Figure 6. The heat release rate of full scale experimental from a scooters fire in a renovated building. [14]

Due to the close connection between the time required for firefighters' rescue operation and the fire protection measures of a building, this research will refer to the 2018 data regarding the time required for dispatch provided by New Taipei City Fire Department. The average time required for the vehicle to arrive at the fire scene is 394.5 seconds (6 min and 34.5 seconds). The standard deviation is 220 seconds. Therefore, the firefighters can arrive at the fire scene within 13 minutes and 54.5 seconds ( +2 standard deviations) for $97.5 \%$ of the fire cases. By taking into consideration the time required to notify the fire and the time required to report the incident, the simulation will end at 600 seconds (10 minutes), which is 15 minutes after the initial ignition of the full-scale fire experiment.

\section{RESULTS AND DISCUSSION}

\subsection{The Difference to Use of an Automatic Fire Sprinkler System}

The temperatures recorded by the 6 sensors, identified as TC- 1 to TC- 6 along the ceiling of the arcade. The fire starts from the ground and at 1.5 meters to the left of the ground directly under the TC-1 sensor and spreads towards the right. The temperature recorded by TC- 1 increases continually until it reaches around $1000^{\circ} \mathrm{C}$. The temperatures recorded by the other sensors decrease as their distances from the fire increase. Even so, TC-6, the furthest sensor from the fire, still recorded a temperature above $300^{\circ} \mathrm{C}$ at 200 seconds into the simulation. The closest sprinkler (sprinkler_1) is activated at 58.4 seconds in Scenario 3. The activation of the sprinkler manages to keep the surrounding temperature below $60^{\circ} \mathrm{C}$. As the fire spread towards the right, it causes sprinkler_2 to activate, which occurs at 145.1 seconds into the simulation and lowers the surrounding temperatures to below $50^{\circ} \mathrm{C}$. The results, which were very similar to Chang [19] full-scale fire experiment with five scooters, shows that the use of automatic fire sprinkler systems can effectively suppress scooter fires and prevent them from further growth [20]. Figure 7 shows a significant difference between the heat release rate of a scooter fire controlled by a sprinkler system and a scooter fire without the use of a sprinkler system. At around 1 minute and 30 seconds, the heat release rate starts to head in different directions. At 3 minutes into the simulation, the fires that are controlled by a sprinkler system showed a heat release rate lower than $1 \mathrm{MW}$; at 4 minutes into the simulation, these heat release rates are 
almost lined up on the x-axis. It can be seen that the use of automatic fire sprinkler systems can effectively lower the temperature and the heat release rate of the fire in the case of arcade fire. Therefore, the spread of fires could be effectively prevented, especially in storefronts or apartments where plywood is used for renovation. Smokeview image shows difference between having sprinkler installed and none in cases of plywood wall burned by scooters fire. (Figure 8)

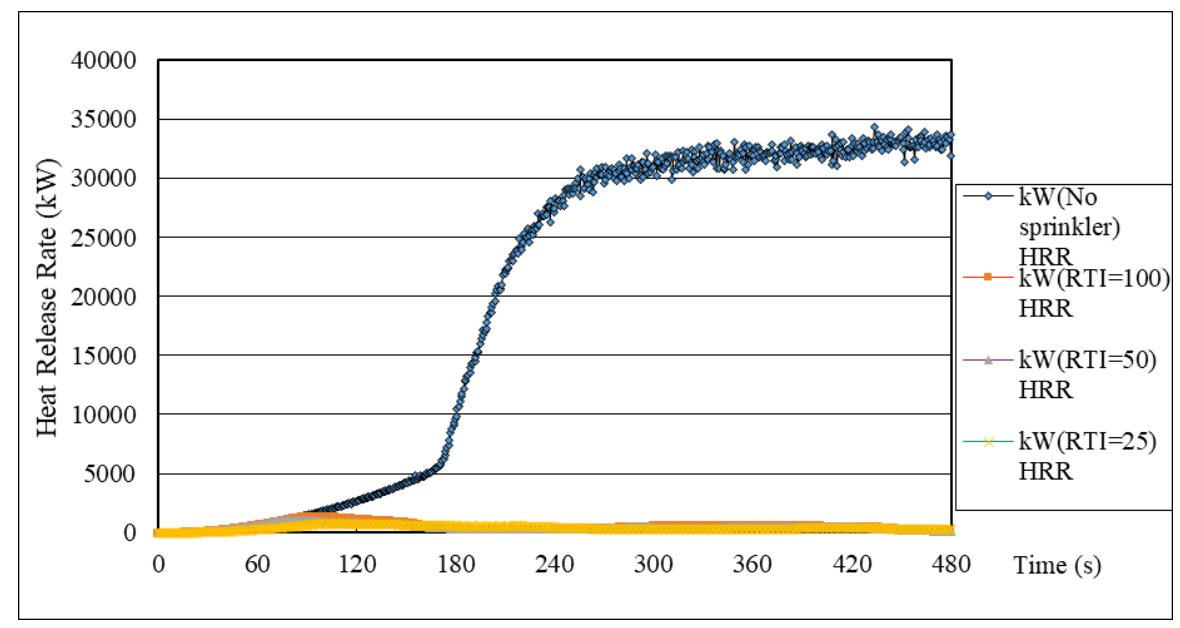

Figure 7. The effects of the sprinklers with different RTIs on the heat release rate.

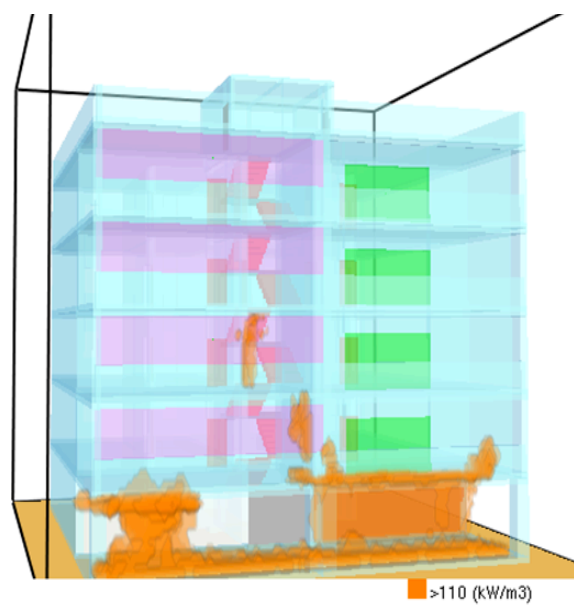

Sprinkler system not installed

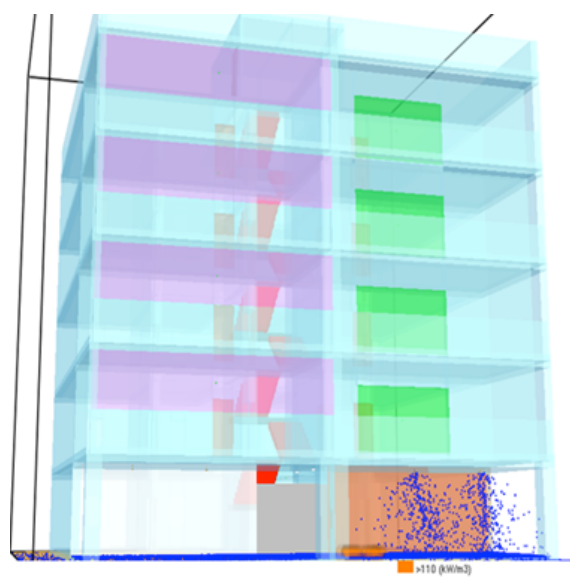

Sprinkler system installed

Figure 8. Difference in the fire without and with the use of sprinklers 


\subsection{Sprinklers with Different RTIs}

Scenarios 1, 2, and 3 of the simulations were designed with sprinklers with RTIs of 100, 50, and 25, respectively. The results of the simulation have shown that Scenario 1 with the highest RTI was activated at the latest (Scenarios 1-Sprinkler_1 time of activation at 78.1 seconds). As shown in Figure 9, this allows the fire to grow larger; the fire had a heat release rate of $1400 \mathrm{~kW}$ at 90 seconds. In the simulation where the sprinkler system was set with an RTI of 50, the maximum heat release rate was below $1000 \mathrm{~kW}$. This can reduce the possibility of ignition of nearby flammable materials and further fire spread. The number of sprinklers activated will also be less with a sprinkler system of lower RTI, allowing for the water to be focused on controlling a smaller fire, which would be more effective in conserving water and reducing fire damage. The heat release rate of Scenario 5 (RTI = 100 , the distance between sprinklers $=2.3 \mathrm{~m}$ ) is compared to the Scenario 1 (RTI $=100$, the distance between sprinklers $=2.6 \mathrm{~m}$. There does not appear to be a significant difference. Therefore, it can be concluded that when the distance between sprinklers is decreased to a number of fewer than 2.6 meters, the effect this has on controlling the heat release rate is less significant than the use of a fast response sprinkler $(\mathrm{RTI} \leqq 50)$.

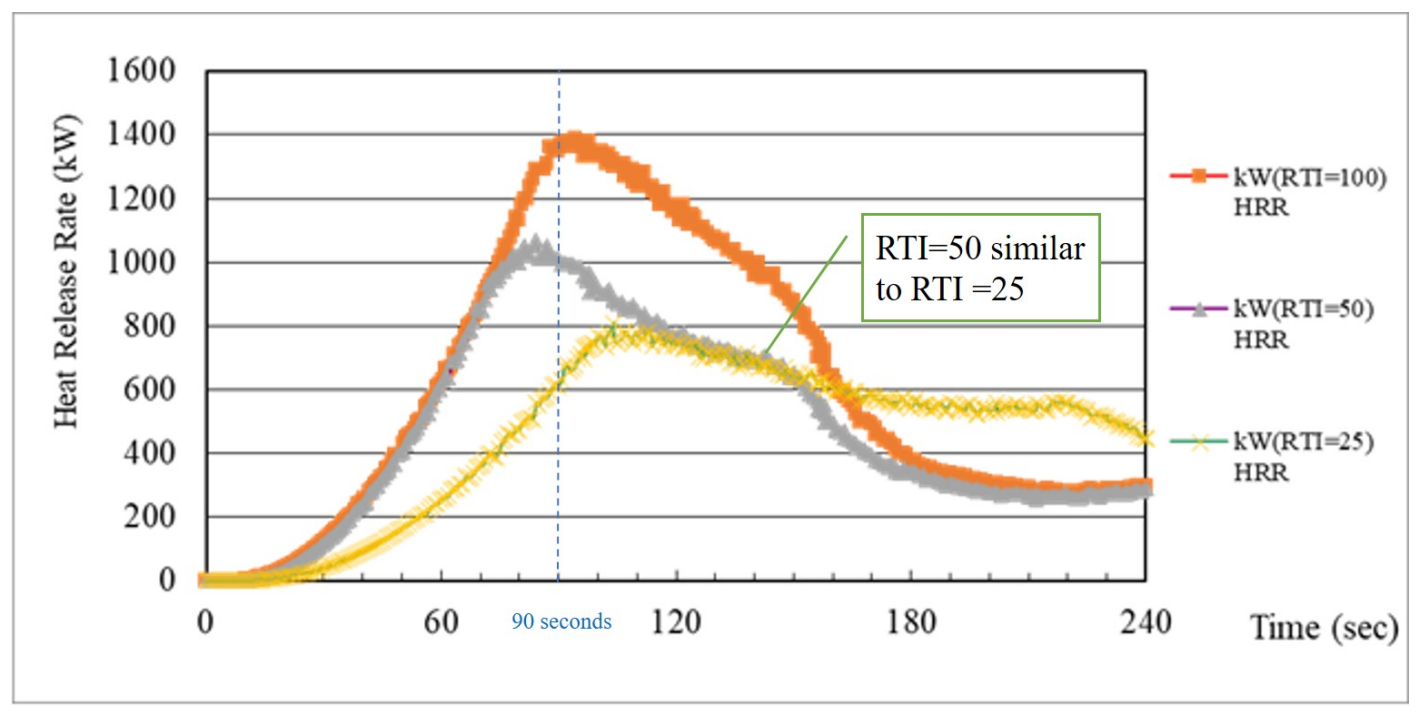

Figure 9. The heat release rate under sprinkler systems of different RTIs.

\subsection{The Same Value of RTI but Different Activation Temperatures}

To further understand the most appropriate sprinkler system for arcades in Taiwan, the difference in the effects of the sprinkler system created by the two most common activation temperatures, which are $68^{\circ} \mathrm{C}$ and $72{ }^{\circ} \mathrm{C}$, are studied. Scenarios 3 and 4, where both RTIs are held constant at 25, are compared to understand the impact that the activation temperatures have on the heat release rate. Experimental results show that the two heat release rate curves are extremely similar. The heat release rate under the sprinkler system with the activation temperature of $72^{\circ} \mathrm{C}$ slightly exceeds the sprinkler system with an activation temperature of $68^{\circ} \mathrm{C}$. Due to the similarity in effects, a fast response sprinkler with either activation temperature of $68^{\circ} \mathrm{C}$ or $72^{\circ} \mathrm{C}$ would both be appropriate when constructing an automatic fire sprinkler system for preventing arcade fires. 


\subsection{When Sprinklers are not Installed}

The sensor TC-22 located at $20 \mathrm{~cm}$ below the ceiling of the arcade at the entrance recorded a temperature of $600^{\circ} \mathrm{C}$ at 240 seconds into the simulation (that shown in Figure 10、11). These values are then applied to the Stefan-Boltzmann Equation [21] (Equation (1)) as follows:

$$
\mathrm{E}=\varepsilon \delta \mathrm{T}^{4} \quad\left(\mathrm{~W} / \mathrm{m}^{2}\right)
$$

where $\mathrm{E}$ is the radiated power per unit area $\left(\mathrm{W} / \mathrm{m}^{2}\right) ; \sigma$ is the Stefan-Boltzmann constant $\left(5.67 \times 10^{-8} \mathrm{~W} / \mathrm{m}^{2}\right.$. $\mathrm{K}^{4}$ ), assuming that the radiant existence is a black body, the emissivity $\varepsilon$ is 1 , and $\mathrm{T}$ is the temperature in Kelvin. Using the temperature recorded by TC-22 at 240 seconds, the radiated power per unit area is $32 \mathrm{~kW} / \mathrm{m}^{2}$. The intensity of fire radiation far exceeds the limitation of a firefighter's personal protective equipment. [22]. Therefore, it is assumed that firefighters would not be able to enter the building for rescue operations under the high temperature created by scooter fires in arcade areas. Under such circumstances, the extinguishment of the fire should be prioritized by the firefighters, and victims in the building should only be rescued after the fire has been controlled.

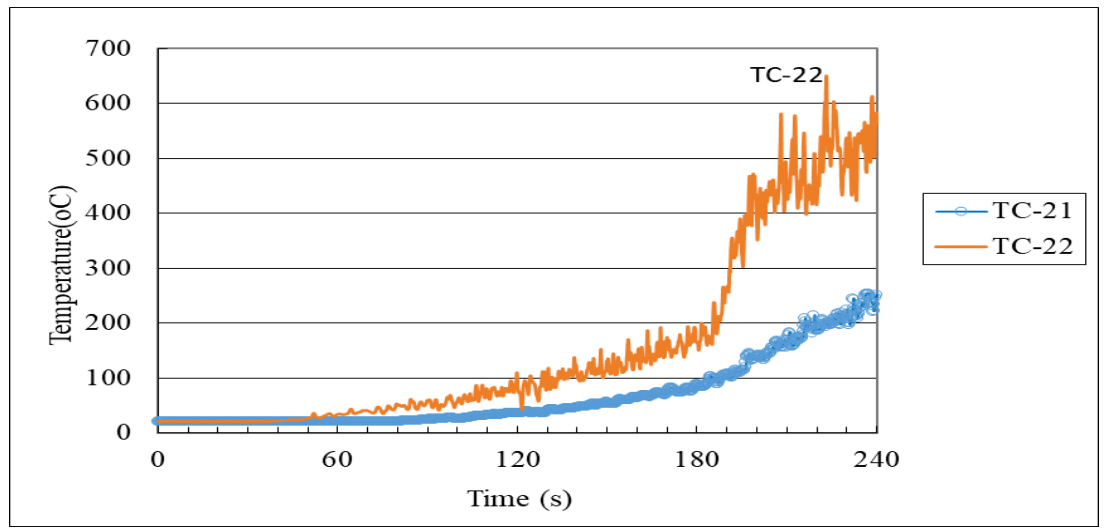

Figure 10. The temperature at the entrance of the building without sprinklers installed
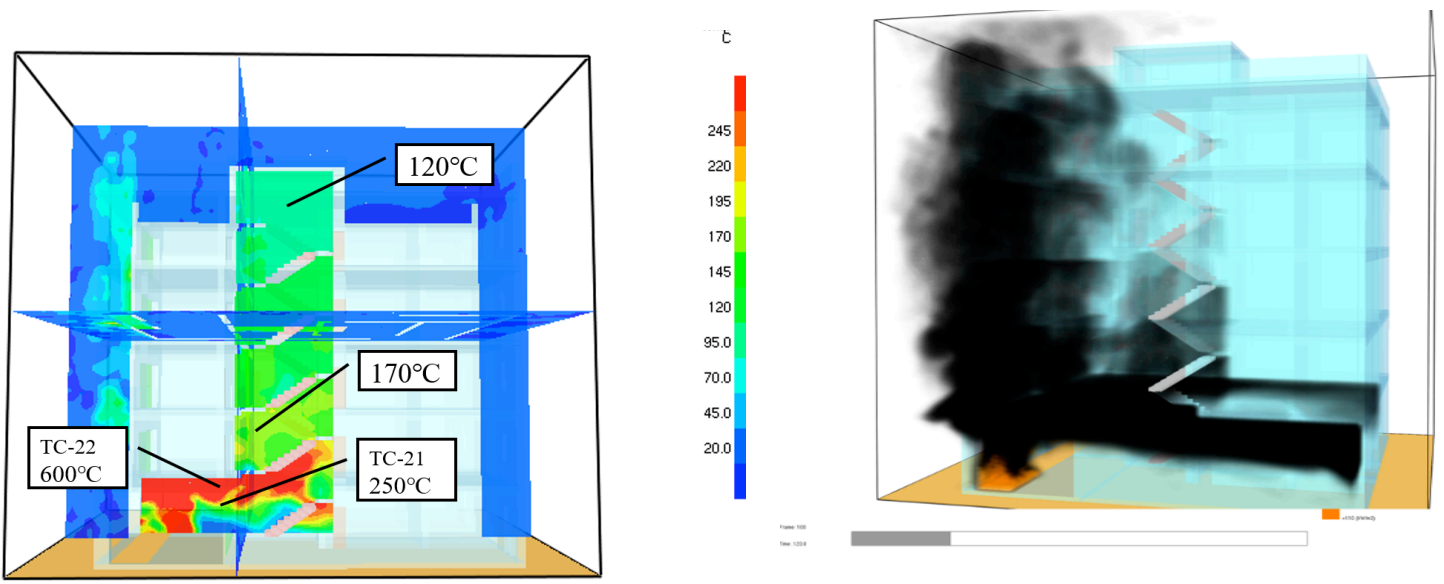

Figure 11. Smoke and fire distribution at 240 seconds in longitudinal section (Sprinkler system not installed) 
This study has resulted in the three key points regarding the performance design of applying an automatic sprinkler system for extinguishing scooter fires in arcade areas. Appropriate use of this design allows for smaller water tank size, which is more acceptable for residents living in Taiwan's compacted cities. Taiwan has approved of sprinkler systems connected to tap water on October 17, 2018 [23]. This design would provide building designers and fire authorities with a convenient solution to improve the fire control abilities beneath the arcade areas.

\section{CONCLUSIONS}

Study shows that when building arcades are not used as paths for pedestrians, there should be practical adjustments, which can be done by installing fire safety measures to reduce fire risks in such type of buildings. First, a significant difference between the heat release rate of a scooter fire controlled by a sprinkler system and a scooter fire without the use of a sprinkler system show that the use of automatic fire sprinkler systems can effectively lower the temperature and the heat release. Second, the quick response sprinkler RTI $\leqq 50$ is the most effective type, and the result is similar to RTI $=25$, the use of low RTI sprinklers help improving fire extinguishing abilities, which also helps to conserve water and reduce fire damage at the same time. appropriate use of wet pipe sprinkler systems and fast response sprinklers $\left(\mathrm{RTI} \leqq 50\right.$ ) with activation temperatures of $68^{\circ} \mathrm{C}$ (or $72^{\circ} \mathrm{C}$ ) are significant factors in the sprinkler system design. When the distance between sprinklers is less than 2.6 meters and the water storage on the rooftop is enough to provide controlling abilities for the sprinkler system for a five-story arcade-style building, the sprinkler system would be able to reduce the risk of fire and disaster relief. Finally, it is recommended that firefighters in the arcade fire should give priority to the fire, and only after the fire is controlled can the victims in the building be rescued.

\section{REFERENCES}

Dong-Ming Lee, 2003, Research on the Spatial Form and Reuse of Traditional Street Houses in Taiwan, Research Report by the Institute of Architecture, Ministry of the Interior, pp.15-26.

Sheng-Chieh Lee, Po-Chuan Huang, Yuan-Shang Lin, 2008, A Preliminary Study of Arcade fires, Journal of Disaster Mitigation and Rescue, Vol.9, No.1, pp.25-42.

Sheng-Chieh Lee, Po-Chuan Huang, Yuan-Shang Lin, 2009, Fire Simulation and Analysis of a Five-Story Building with Residential and Commercial Complexes, Journal of Disaster Mitigation and Rescue, Vol.10, No.1, pp.63-82.

John H. Mammoser III, Francine Battaglia, 2004, A Computational Study on the Use of Balconies to Reduce Flame Spread in High-Rise Apartment Fires, Fire Safety Journal, pp.277-296.

Su Chung-Hwei, Shyu Ming-Jhih and Huang Guo-Je, 2010, Stack Effect of Smoke in an Old Apartment Staircase in Taiwan, The Proceedings of International Symposium on Safety Science and Technology.

C.-Y. Lin, 2000, The Burning Behavior of Motorcycles, Journal of Chinese Institute of Engineers, 23:1, pp. 9-18.

Morgan J. Hurley, Editor-in-Chief, 2016, SFPE Handbook of Fire Protection Engineering, ISBN 978-1-4939-2564-3 ISBN 978-1-4939-2565-0 (eBook), Society of Fire Protection Engineers, p2067.

Ming-Hwa Chung, Shih-Feng Kao, Yu-Shiang Wu, Chi-Jan Huang, Kuan-Yung Chang, 2009, Fire Safety Improvement with FDS Simulation for Old Apartment Buildings, Journal of Applied Fire Science(EI), Vol. 18, Issue 4, pp. 317-335. 
Jason E. Floyd, K. B. McGrattan, 2003, CFD Fire Simulation Using Mixture Fraction Combustion and Finite Volume Radiative Heat Transfer, Journal of Fire Protection Engineering, Vol.13.

Cherng-Shing Lin, Te-Chi Chen, Chia-Chun Yu, Kuo-Ta Chou, Chao-Hsing Chang, 2009, Computer Field Model Simulation of an Old Five-story Building, Industrial Safety \& Health Technology, pp. 46-56.

K.B. McGrattan, H. R. Baum, R.G. Rehm, 1998, Large Eddy Simulations of Smoke Movement, Fire Safety Journal, Vol.30, pp.161-178.

Kevin McGrattan, Simo Hostikka, Randall McDermott, Jason Floyd and Marcos Vanella, June 26,2018, Fire Dynamics Simulator User's Guide, NIST Special Publication 1019-Sixth Edition.

Glenn P. Forney, June 22, 2018, Smokeview, A Tool for Visualizing Fire Dynamics Simulation Data Volume I: User's Guide, NIST Special Publication 1017-1 Sixth Edition.

Chin-Hsing Huang, Ying-Ji Chuang, Chieh-Hsin Tang, and Ching-Yuan Lin, January 2006, Experimental Study on Spread of Fires Started by Scooters in the Sheltered Arcade of Arcade-Style Buildings, Journal of Applied Fire Science 16(3):235-247. pp.16.

R. E. Solomon, 1997, Automatic Sprinkler Systems, Fire Protection Handbook Eighteenth Edition, National Fire Protection Association, Quincy, pp. 6-139.

Meng-Chieh Tien, Ching-Te Chao, 2009, Automatic Sprinkler Systems, Chan's Arch-Publishing, pp. 161.

M.-J. Tsai, C.-W. Wu, C.-Y. Lin, 2004, Development and Application of a Large Scale Fire Products Collector, Journal of the Chinese Society of Mechanical Engineers, 25:3, pp. 267-276.

Han-Tao Zheng, 2008, Simulating E-Coefficient of Motorcycle Fire with FDS, Journal of Central Police University, pp. 16.

Shang-Wen Chang, 2008, Effect and Prospect of Sprinkler System in Motorcycle Fire under Arcade, Building Research Newsletter, Vol. 59.

Shang-Wen Chang, Ching-Yuan Lin, Peng-Chin Wang, Chien-Jung Chen and Pang-An Hsiao, Dec. 2006, Experimental Studies on Fire Suppression Effectiveness of Sprinkler in Motorcycle Fires, Journal of Architecture, Vol.58, pp.171-182.

D. Drysdale, March 2003, An Introduction to Fire Dynamics-Second Edition, John Wiley \& Sons, pp. 52-57.

A. Bergqvist, 20-21 Nov, 2003, What Can Fire Brigade Do About Catastrophic Tunnel Fires, Proceedings of the International Symposium on Catastrophic Tunnel Fire, pp.105-116.

The National Fire Agency, Ministry of the Interior (Taiwan), 2018, Amend the "Standards for Fire Safety Equipment Installation in Various Places", NO.1070822946.

https://law.nfa.gov.tw/GNFA/news.aspx?id=1735 